\title{
Physical fitness in young adults born preterm
}

Marjaana Tikanmäki, MD ${ }^{\mathrm{a}, \mathrm{b}}$, Tuija Tammelin, $\mathrm{MSc}^{\mathrm{c}}$, Marika Sipola-Leppänen, MD ${ }^{\mathrm{a}, \mathrm{b}, \mathrm{d}}$, Nina Kaseva, MD, PhD ${ }^{\mathrm{a}, \mathrm{e}}$, Hanna-Maria Matinolli, MHealthSci ${ }^{\mathrm{a}, \mathrm{b}}$, Satu Miettola, MD ${ }^{\mathrm{a}, \mathrm{b}, \mathrm{f}}$, Johan G Eriksson, $\mathrm{MD}, \mathrm{DMSc}^{\mathrm{g}, \mathrm{h}}$, Marjo-Riitta Järvelin, $\mathrm{MD}, \mathrm{PhD}^{\mathrm{i}, \mathrm{j}, \mathrm{k}, \mathrm{l}}$, Marja Vääräsmäki, $\mathrm{MD}, \mathrm{PhD}^{\mathrm{f}, \mathrm{m}}$ and Eero Kajantie, $\mathrm{MD}, \mathrm{PhD}^{\mathrm{a}, \mathrm{e}, \mathrm{f}}$

Affiliations: ${ }^{\mathrm{a} C h r o n i c}$ Disease Prevention Unit, National Institute for Health and Welfare, Oulu and Helsinki, Finland; ${ }^{b}$ Institute of Health Sciences, University of Oulu, Oulu, Finland; ' $L I K E S$ Research Center for Sport and Health Sciences, Jyväskylä, Finland; ${ }^{d}$ Department of Pediatrics and Adolescence, Oulu University Hospital, Oulu, Finland; ${ }^{~}$ Children's Hospital, Helsinki University Hospital, University of Helsinki, Helsinki, Finland; ${ }^{\mathrm{f}}$ Department of Obstetrics and Gynaecology, Medical Research Center Oulu, Oulu University Hospital and University of Oulu, Oulu, Finland; ${ }^{g}$ Department of General Practice and Primary Health Care, University of Helsinki and Helsinki University Hospital, Helsinki, Finland; h Folkhälsan Research Centre, Helsinki, Finland; ${ }^{i}$ Department of Epidemiology and Biostatistics, MRC Health Protection Agency (HPA) Centre for Environment and Health, School of Public Health, Imperial College London, London, United Kingdom; ${ }^{\mathrm{j} C e n t e r}$ for Life Course Epidemiology, Faculty of Medicine, University of Oulu; ${ }^{k}$ Biocenter Oulu, Oulu, Finland; ' ${ }^{\text {Unit }}$ of Primary Care, Oulu University Hospital, Oulu, Finland; and ${ }^{\mathrm{m}}$ Children, Adolescents and Families, National Institute for Health and Welfare, Oulu, Finland.

Address correspondence to: Marjaana Tikanmäki, Department of Health, Chronic Disease Prevention Unit, National Institute for Health and Welfare, P.O. Box 310, 90101 Oulu, Finland [marjaana.tikanmaki@thl.fi]

Short title: Physical fitness in young adults born preterm

Funding Source: The ESTER study was supported by grants from the Academy of Finland (SALVE program for 2009-2012 and grants 127437, 129306, 130326, 134791 and 263924 to EK), Doctoral Programme for Public Health, University of Tampere (to MSL), the Emil Aaltonen Foundation (to EK), European Commission (Framework 5 award QLG1-CT-2000-001643; to MRJ), the Finnish Foundation for Pediatric Research (to EK), the Finnish Government Special Subsidiary for Health Sciences (evo) (to JGE), Finnish Medical Societies: Duodecim (to EK) and Finska Läkaresällskapet (to JGE and NK), the Jalmari and Rauha Ahokas Foundation (to EK), the Juho Vainio Foundation (to EK and MSL), the National Graduate School of Clinical Investigation (to MT), the Novo Nordisk Foundation (to EK and MV), the Signe and Ane Gyllenberg Foundation (to EK and JGE), the Sigrid Jusélius Foundation (to EK), and the Yrjö Jahnsson Foundation (EK, MSL and MV).

Financial Disclosure: The authors report no financial relationships relevant to this article.

Potential Conflict of Interest: The authors report no potential conflicts of interest.

Abbreviations: CI - Confidence interval; EPT, early preterm ( $<34$ gestational weeks); ESTER ESTER Preterm Birth Study "Ennenaikainen syntymä ja aikuisiän terveys; Preterm birth and early life programming of adult health and disease"; FMBR - the Finnish Medical Birth Register; GDM Gestational diabetes mellitus; LGA - Large for gestational age; LPT, late preterm (34-36 gestational weeks); METh - Metabolic equivalent hours; N - Newton; NFBC - Northern Finland Birth Cohort 1986; SGA - Small for gestational age; SD - Standard deviation

Key Words: premature birth, physical fitness, physical activity

\section{What's Known on This Subject}

Young adults born preterm have higher levels of cardiometabolic risk factors and lower physical activity than term-born peers. Earlier studies, limited to those born very preterm or at very low birth weight, also suggest lower physical fitness in this group. 
45 What This Study Adds

46 Young adults born preterm have lower muscular fitness and rate themselves as being less fit than

47 those born at term. There was no difference in cardiorespiratory fitness in this sample across the 48 entire range of preterm birth versus the controls. 
51 Dr. Tikanmäki designed and carried out the initial analyses, drafted the initial manuscript, participated in 52 data collection, and approved the final manuscript as submitted.

53 Drs. Tammelin, Sipola-Leppänen and Vääräsmäki participated in the study design and data collection and 54 reviewed, revised, and approved the final manuscript as submitted.

55 Ms. Matinolli and Dr. Miettola participated in the data collection and reviewed, revised and approved the 56 final manuscript as submitted. Dr. Kaseva participated in the study design (focus on the analyses) and reviewed, revised and approved the final manuscript as submitted. Drs. Eriksson and Järvelin participated in the study design and data collection and reviewed, revised and approved the final manuscript as submitted.

61 Dr. Kajantie conceptualized and designed the study, was responsible for the data collection, and reviewed, revised and approved the final manuscript as submitted. 


\section{Abstract}

Background: Young adults born preterm have higher levels of cardiometabolic risk factors than their term-born peers. Muscular and cardiorespiratory fitness are strong predictors of cardiometabolic health and have many other health benefits. We assessed muscular, cardiorespiratory, and self-rated fitness in preterm-born young adults.

Methods: We studied unimpaired participants of the ESTER birth cohort study at age 23.3 (SD 1.2) years: 139 born early preterm ( $<34$ weeks; EPT), 247 born late preterm ( 34 to 36 weeks; LPT), and 352 born at term (control group). We measured muscular fitness with the number of modified pushups performed in 40 seconds and maximal hand grip strength $(\mathrm{N})$ of the dominant hand, cardiovascular fitness withheart rate at the end of a 4-minute step test, and self-rated fitness.and Data was analyzed with linear regression.

Results: Both young adults born EPT (-0.8 [95\% CI-1.5; -0.1; adjusted for sex, age and source cohort]) and LPT (-0.8 [-1.4; -0.3]) performed fewer modified push-ups in 40 seconds than controls. Hand grip strength was $23.8 \mathrm{~N}(0.9-46.8)$ lower in EPT. Cardiorespiratory fitness, measured by submaximal step test, was similar. On a self-rated fitness scale (1-5), the EPT adults reported on average $0.2(0.0 ; 0.4)$ lower scores than controls. After adjustment for early life confounders, the results remained. They attenuated after further adjustment for mediating factors.

Conclusions: Young adults born EPT and LPT had lower muscular fitness than controls, which may predispose them to cardiometabolic and other chronic diseases. Adults born EPT also perceived themselves less fit than controls. 


\section{Introduction}

87 Every year approximately 14.9 million babies worldwide, $11 \%$ of all newborns, are born preterm

88

(<37 weeks of gestation). ${ }^{1}$ Long-term follow-up studies have focused on those born smallest and most immature, who have increased levels of cardiometabolic risk factors as adolescents or adults.

${ }^{2,3}$ However, the majority of preterm infants are born closer to full-term: in the U.S., for example, $70 \%$ of them are born late preterm, between 34 and 36 weeks of gestation. ${ }^{4}$ The adverse consequences of preterm birth have also been suggested to be present in those born less preterm and increase with the degree of prematurity. ${ }^{5}$

Adolescents and adults born preterm at very $(<1500 \mathrm{~g})$ or extremely $(<1000 \mathrm{~g})$ low birth weight report undertaking less physical activity than those born at term, ${ }^{6-8}$ although these associations have not been captured by studies using an objective measurement of physical activity (e.g., accelerometry). ${ }^{9,10}$ Lower muscular and cardiorespiratory fitness are also features of those born preterm at extremely low birth weight. ${ }^{8,11}$ Few studies have assessed this in adolescents or adults born less preterm; a study in Swedish male conscripts was consistent with a graded relationship between lower length of gestation and lower maximal exercise capacity. ${ }^{12}$ This question is important because both cardiorespiratory and muscular fitness are independent predictors of cardiometabolic and musculoskeletal health ${ }^{13-15}$ and lower late-life mortality. ${ }^{16,17}$

We studied the association of early ( $<34$ weeks) and late (34 to 36 weeks) preterm birth with muscular, cardiorespiratory, and self-rated physical fitness among young adults. We further examined the roles of prenatal and early life factors as potential confounders and current health characteristics as mediators of fitness level. 


\section{Methods}

\section{Participants}

The participants come from the ESTER Preterm Birth Study, which comprises 1890 young adults (Supplemental Figure 1). They were recruited among the Northern Finland Birth Cohort 1986 (NFBC; 49.8\%) born in 1985-1986 and among all children (50.2\%) born from 1987 to 1989 in the same geographical area, identified via the Finnish Medical Birth Register (FMBR) ${ }^{5}$ In 2009-2011, 750 individuals with adequately verified lengths of gestation participated in a clinical study at 23.3 (SD 1.2) years. ${ }^{18}$ Those who were pregnant $(n=18)$ or reported cerebral palsy $(n=6)$, mental disability ( $n=7)$, and/or other severe physical disability $(n=3)$ were excluded. This left us with 139 participants born early preterm, 247 late preterm, and 352 born after 37 completed weeks of gestation (referred to as "at term"), who served as controls. Of those invited as born early preterm, late preterm and as controls, $41.6 \%, 39.5 \%$, and $35.9 \%$ participated, respectively. According to a detailed non-participant analysis of the clinical examination, men were less likely to participate among the late preterm and control groups; there was no difference in perinatal characteristics between participants and non-participants in any of the groups. When we compared participants of the clinical examination included in analyses of specific outcomes with those not included (Supplemental Figure 1), early preterm participants were less likely to be included in analyses of handgrip strength $(\mathrm{p}=0.04)$ and self-perceived fitness $(\mathrm{p}=0.01)$.

\section{Ethics}

The study was approved by the Coordinating Ethics Committee at Helsinki and Uusimaa Hospital District. Participants provided written informed consent. 


\section{Perinatal data}

129 Perinatal data for participants recruited through the NFBC came from the cohort database,

130 originally collected from hospital and maternal welfare clinic records. ${ }^{19} \mathrm{We}$ collected corresponding

131 data for those invited through the FMBR. Length of gestation (determined by ultrasound in $62.7 \%$

132 of preterm infants and $53.1 \%$ of controls, by last menstrual period in $36.8 \% / 46.9 \%$, and from

133 hospital records with no data on method of determination in $0.5 \% / 0.0 \%$, respectively) ${ }^{18}$ and

134 diagnoses of maternal gestational diabetes (GDM), hypertension (gestational or chronic), or

135 preeclampsia (including superimposed) according to prevailing criteria were confirmed by

136 reviewing original hospital records. ${ }^{20,21}$ Small for gestational age (SGA) was defined as birth weight

137 SD score $<-2$ SD and large for gestational age (LGA) as > 2 SD according to Finnish standards. ${ }^{22}$

\section{Clinical examination}

139 Body weight and composition were assessed using segmental multi-frequency bioelectrical

140 impedance (InBody 3.0, Biospace Co., Seoul, Korea). Spirometry was performed before physical

141 fitness tests and repeated after inhalation of $400 \mu \mathrm{g}$ salbutamol if it suggested airflow obstruction. ${ }^{23-}$

$142{ }^{25}$ The participants completed questionnaires on their medical history, including history of asthma,

143 medications, socioeconomic status, physical activity and daily smoking. Childhood socioeconomic

144 status was assessed as the educational attainment of the higher educated parent, . Physical activity

145 level was calculated in METh (metabolic equivalent hours) per week based on a questionnaire on 1)

146 light (assuming a value of 3 MET), 2) moderate to vigorous (5 MET), and 3) commuting physical

147 activity (4 MET). ${ }^{26,27}$

\section{Outcomes}

149 As a measure of short-term endurance capacity of the upper body and the ability to stabilize the trunk, the participants performed the $40 \mathrm{~s}$ modified push-up test. The participant lay prone on a mat,

151 clasped hands behind the back, performed a straight-leg push-up with the elbows completely 
straight in the up position, touched one hand on the top of the supporting hand, and returned to the prone position to repeat the cycle. The participants practiced one push-up cycle before the test. ${ }^{28,29}$ For the handgrip test, the maximal isometric strength of the dominant hand was measured by a dynamometer (Good Strength, IGS01, Metitur Oy, Jyväskylä, Finland) based on the strain-gauge technique. ${ }^{29,30}$ Cardiorespiratory fitness was measured using the Åstrand-Ryhming step test, ${ }^{31,32}$ during which the participant steps on and off a bench $(33 \mathrm{~cm}$ high for women and $40 \mathrm{~cm}$ for men) repeatedly for four minutes at 23 steps per minute, paced by a metronome. Heart rate was monitored by a Polar monitor $\left(\mathrm{RS} 800 \mathrm{CX}^{\mathrm{TM}}\right.$ training computer and WearLink® W.I.N.D. transmitter, Polar Electro Oy, Kempele, Finland) and recorded right after the test. Self-rated fitness was measured with a question: "How do you consider your current physical fitness?" The response alternatives were very good, quite good, fair, quite poor and very poor. ${ }^{33}$ The scale was reversed $(1=$ very poor, $5=$ very good) for clarity.

\section{Statistical methods}

All analyses were performed using SPSS, Versions 21.0 and 22.0 (IBM/SPSS, Chicago, Illinois, USA). We compared descriptive characteristics by Student's $t$-test and $\chi^{2}$-test, and the outcomes using linear regression with a significance level of $<0.05$. We tested for interactions between two variables (significance level $P<0.01$ ) by including a product term together with these variables. Categorical adjusting variables were entered as dummy variables, with a separate dummy for missing values. In Model 1 we adjusted for sex, age, and cohort. In Model 2, we further adjusted for parental and early life potential confounders: educational attainment of the higher educated parent, maternal GDM and hypertension, and birth weight SD score. In Model 3 we additionally adjusted for potential adult mediators that may differ between those born preterm and at term: self-reported physical activity, ${ }^{6,7}$ diagnosed asthma, ${ }^{34}$ height,${ }^{6,7}$ body fat percentage ${ }^{5}$, and smoking. ${ }^{35}$ For heart rate after the step test, we also adjusted for whether the participant had received salbutamol in a bronchodilation test. We identified specific covariates altering the associations by adding or 
removing the variables step-wise. We reran the analyses after replacing the adjustment for body fat percentage with lean body mass. As a sensitivity analysis, we also reran the analyses 1) after exclusion of subjects with asthma and 2) after inclusion of subjects with a known chronic condition affecting mobility who were excluded from the main analyses.

\section{Results}

Participant characteristics are shown in Table 1 and outcomes by exposure group in Table 2. Correlations between the outcomes and associations between covariates and outcomes are shown in Supplemental Files. There was no interaction between the association of sex and preterm birth with the outcomes.

\section{Modified push-up test}

On average, women performed 10.4 (SD 2.0) push-ups in 40 seconds and men 14.4 (SD 3.7). Participants born early and late preterm performed an average of 0.8 fewer push-ups than did the controls. The difference remained similar when adjusted for socioeconomic status and pregnancyrelated factors but attenuated when adjusted for adult characteristics including body fat percentage (Figure 1, Supplemental Table 1) or lean body mass instead.

\section{Hand grip strength}

The mean hand grip strength was 352.1 (SD 82.4) $\mathrm{N}$ among women and 643.1 (SD 145.7) N among men. Those born early preterm had $23.8 \mathrm{~N}$ lower hand grip strength than controls, when adjusted for sex, age and cohort. This difference attenuated after adjustment for socioeconomic status and pregnancy-related factors, mainly because of adjustment for birth weight SD score. Further adjustment for adult characteristics, including body fat percentage or lean body mass, had little effect on the association. Those born late preterm had similar hand grip strength than controls (Figure 1, Supplemental Table 1). 


\section{Step test}

201 The mean heart rate after the step test was 160 (SD 14) beats/min among women and 153 (SD 16)

202 beats/min among men. There was no difference between either of the preterm groups and controls.

203 When further adjusted for adult characteristics, those born early preterm had 2 beats/min $(P=0.24)$

204 and those born late preterm 3 beats/min lower heart rate $(P=0.02)$, indicating better

205 cardiorespiratory fitness. The change in the mean difference was mainly due to adjustment for adult 206 body fat percentage (Figure 1, Supplemental Table 1).

207

\section{Self-rated fitness}

The mean score for self-rated fitness on a scale ranging from one (very poor) to five (very good) was 2.3 (SD 0.8) for women and 2.6 (SD 0.9) for men. Participants born early preterm scored 0.2 points lower than controls. Better self-rated fitness correlated with better measurements of physical fitness. This correlation was weakest for hand grip strength, in particular among participants born early preterm (Supplemental Table 2). The difference remained similar when adjusted for socioeconomic status and pregnancy-related factors and attenuated when adjusted for adult characteristics (Figure 1, Supplemental Table 1), mainly due to adjustments for body fat percentage and physical activity level (not shown).

\section{Sensitivity analyses}

Participants with asthma had 23.0 N (95\% CI 0.8; 45.3) weaker hand grip strength, 3 beats/min $(95 \%$ CI $0.2 ; 6.2)$ higher heart rate after the step test, 0.2 points $(95 \%$ CI $0.0 ; 0.4)$ poorer selfperceived fitness level, and a similar number of modified push-ups $(0.2,95 \% \mathrm{CI}-0.5 ; 0.9)$ compared with those with no asthma (adjusted for sex, age and cohort). We reran the analyses after exclusion of participants with asthma. The results remained similar. We also reran the analyses to include physically impaired participants excluded from the original analyses. Again, the results 
remained. For the step-test, we excluded those who had inhaled salbutamol during spirometry

224 before the step test; the results remained.

225

\section{Pre- and neonatal factors}

As a continuous variable, one week longer length of gestation predicted 0.1 (95\% CI 0.0-0.2) more push-ups and 0.02 (0.01-0.04) higher scores in self-perceived fitness scale. One unit higher birth weight SD score predicted 16.7 N (9.9-23.5) increase in hand grip strength. Participants born SGA had $70.0 \mathrm{~N}(95 \% \mathrm{CI} 36.4 ; 97.5)$ weaker hand grip strength than the remaining participants when adjusted for sex, age, cohort, and stage of preterm birth. No difference was seen for the other outcomes. When SGA-participants were excluded, the differences in hand grip strength between groups attenuated and became statistically non-significant. Other results remained similar.

Of the participants born early preterm, 21 received supplementary oxygen for 28 days or longer after birth. They had similar fitness as the remaining participants born early preterm.

\section{Discussion}

Our main finding was that young adults born early and late preterm performed fewer modified push-ups and those born early preterm had lower hand grip strength in comparison with the control group. Cardiorespiratory fitness was, however, not lower. Young adults born early preterm rated themselves less fit than controls.

\section{Muscular fitness}

In the modified push-up test, young adults born early or late preterm performed on average one push-up less than controls. For comparison, 17-year-olds born at $800 \mathrm{~g}$ or less performed 5-6 fewer push-ups and exhibited lower performance in other tests measuring muscular fitness than controls. ${ }^{8}$ The difference in our study was not explained by socioeconomic status, pregnancy-related factors, or the level of current physical activity and lean body mass. An exception was adjustment for body 
fat percentage, which attenuated the associations. This suggests that the higher adiposity of adults born preterm may in part explain their lower performance in the modified push-up test as the test requires supporting one's body weight.

Hand grip strength is a well-established predictor of future physical function, disease risk, and mortality. ${ }^{16,17,36-38}$ Low birth weight is consistently associated with reduced hand grip strength in children, adolescents, and adults. A meta-analysis reported age-adjusted results with approximately $2 \mathrm{~kg}(20 \mathrm{~N})$ higher muscle strength per kilogram higher birth weight. ${ }^{39}$ Our findings show a $2.4 \mathrm{~kg}$ $(23.8 \mathrm{~N})$ difference in hand grip strength between the early preterm group and controls. This difference was largely explained by the lower birth weight SD score of those born early preterm.. An approximate estimate of its consequences is provided by a meta-analysis reporting an overall summary hazard ratio of 0.93 for mortality associated with a $2.5 \mathrm{~kg}$ increase in hand grip strength. ${ }^{16}$

\section{Cardiorespiratory fitness}

Against our hypothesis, cardiorespiratory fitness measured by step test was not lower among young adults born preterm. The confidence interval extended no further than 0.27 SD from zero, indicating we could exclude all but small differences between groups. Several, although not all, ${ }^{40}$ studies have shown lower cardiorespiratory fitness among children and young people born extremely $(<28$ weeks) or very ( $<32$ weeks) preterm or at extremely or very low birth weight using a maximal exercise test ${ }^{10,11,40-43}$ or a submaximal test ${ }^{8,41}$ as in our study. A study in 218,820 Swedish male conscripts showed that among those born 32 to 36 weeks maximal exercise capacity was 0.10 SD lower than among term-borns ${ }^{12}$; such a small difference would not have been detected in the present study. Together with these studies, our study suggests that lower levels of cardiorespiratory fitness are not present across the whole range of preterm births at least at any meaningful level. ${ }^{44-46}$ 


\section{Self-rated fitness}

Correlations between self-rated and objectively measured cardiorespiratory fitness were similar to those previously observed. ${ }^{47}$ They were also similar within groups, indicating that adults born preterm and at term estimate their fitness equally well. This was also true for the modified push-up test, whereas correlations between self-rated fitness and hand grip strength were weak. We are aware of one previous study reporting that young adults born with extremely low birth weight expressed less physical self-confidence. ${ }^{48}$ The difference we found between early preterm and control groups was relatively weak -0.2 points lower scores . The association was not explained by socioeconomic status or pregnancy-related factors. However, adjustment for adult characteristics such as physical activity and body fat percentage attenuated the results, suggesting a mediating role in the association of early preterm birth and self-perceived fitness. The role of leisure time physical activity and body mass index in determining self-perceived health and fitness has been shown earlier ${ }^{49}$ and is also supported by our results .

\section{Implications}

Lower muscular fitness is associated with early and possibly also late preterm birth. This may predispose people born preterm to cardiometabolic diseases in concert with other risk factors, including higher blood pressure and impaired glucose regulation. ${ }^{2,3}$ Low muscular fitness is also associated with other health disadvantages including poorer bone health ${ }^{15}$ and is a well-established predictor of mortality in later adulthood. ${ }^{16,17}$ Lower muscular fitness may partly be a consequence of previously observed lower conditioning physical activity levels among young adults born preterm, ${ }^{6-8}$ which in turn could originate from poorer motor skills or reduced pulmonary function. ${ }^{50}$ Our findings ${ }^{3}$ emphasize promotion of physical activity, in particular activity to enhance muscular fitness, across the whole range of preterm birth from early childhood onwards ${ }^{51}$ A healthy lifestyle adopted in childhood is likely to carry on into adulthood. ${ }^{52}$ In addition to these practical 
implications, our results concur with the large body of evidence from human and animal studies suggesting that individual differences in physical activity and fitness originate from early life. ${ }^{53}$

\section{Strengths and limitations}

The strengths of our study include measurement of muscular fitness, assessed in two ways, and cardiorespiratory fitness, and a study population enabling the evaluation of physical fitness across the full range of preterm birth. A detailed non-participation analysis ${ }^{5}$ raised little concern over participation bias. Participants of the clinical examination who could not be included in analyses of handgrip and self-perceived fitness were more likely to be born early preterm; this would be expected to result in more conservative estimates. We had access to reliable and diverse perinatal data, including verified length of gestation. However, an accurate estimation of cardiorespiratory fitness would require maximal exercise testing with a direct measurement of oxygen uptake.

\section{Conclusions}

We found that young adults born preterm have lower muscular fitness, as individuals born either early preterm or late preterm performed fewer modified push-ups and those born early preterm had lower hand grip strength. No difference existed in cardiorespiratory fitness. Young adults born early preterm perceived themselves to be less fit than did the controls. The differences we found may increase the risk of chronic adult disease in later life. For pediatricians and allied health professionals, they call for promotion of physical activity in children born both early and late preterm, with a particular focus on promoting physical activity that enhances muscular fitness.

\section{References}

1. Blencowe H, Cousens S, Oestergaard MZ, Chou D, Moller A-B, Narwal R, et al. National, regional, and worldwide estimates of preterm birth rates in the year 2010 with time trends since 1990 for selected countries: a systematic analysis and implications. Lancet. 2012;379(9832):2162-2172. 
2. Johansson S, Iliadou A, Bergvall N, Tuvemo T, Norman M, Cnattingius S. Risk of high blood pressure among young men increases with the degree of immaturity at birth. Circulation.

3. Kajantie E, Hovi P. Is very preterm birth a risk factor for adult cardiometabolic disease? Semin Fetal Neonatal Med. 2014;19(2):112-117.

4. Martin JA, Osterman MJ. Preterm births - United States, 2006 and 2010. MMWR Surveill Summ. 2013;62(Suppl 3):136-138.

5. Sipola-Leppanen M, Vaarasmaki M, Tikanmaki M, Matinolli HM, Miettola S, Hovi P, et al. Cardiometabolic Risk Factors in Young Adults Who Were Born Preterm. Am J Epidemiol. 2015; First published online May 5, 2015 doi:10.1093/aje/kwu443(

6. Kajantie E, Strang-Karlsson S, Hovi P, Raikkonen K, Pesonen AK, Heinonen K, et al. Adults born at very low birth weight exercise less than their peers born at term. J Pediatr. 2010;157(4):610-616, 616 e611.

7. Kaseva N, Wehkalampi K, Strang-Karlsson S, Salonen M, Pesonen AK, Raikkonen K, et al. Lower conditioning leisure-time physical activity in young adults born preterm at very low birth weight. PLoS One. 2012;7(2):e32430.

8. Rogers M, Fay TB, Whitfield MF, Tomlinson J, Grunau RE. Aerobic capacity, strength, flexibility, and activity level in unimpaired extremely low birth weight $(\leq 800 \mathrm{~g})$ survivors at 17 years of age compared with term-born control subjects. Pediatrics. 2005;116(1):e58-65.

9. Kaseva N, Martikainen S, Tammelin T, Hovi P, Järvenpää A-L, Andersson S, et al. Objectively measured physical activity in young adults born preterm at very low birth weight. J Pediatr. 2015;166(2):474-476.

10. Welsh L, Kirkby J, Lum S, Odendaal D, Marlow N, Derrick G, et al. The EPICure study: maximal exercise and physical activity in school children born extremely preterm. Thorax. 2010;65(2):165172.

11. Burns YR, Danks M, O'Callaghan MJ, Gray PH, Cooper D, Poulsen L, et al. Motor coordination difficulties and physical fitness of extremely-low-birthweight children. Dev Med Child Neurol. 2009;51(2):136-142.

12. Svedenkrans J, Henckel E, Kowalski J, Norman M, Bohlin K. Long-Term Impact of Preterm Birth on Exercise Capacity in Healthy Young Men: A National Population-Based Cohort Study. PLoS One. 2013;8(12):e80869.

13. Kodama S, Saito K, Tanaka S, Maki M, Yachi Y, Asumi M, et al. Cardiorespiratory fitness as a quantitative predictor of all-cause mortality and cardiovascular events in healthy men and women: a meta-analysis. JAMA. 2009;301(19):2024-2035.

14. Artero EG, Lee D-c, Lavie CJ, España-Romero V, Sui X, Church TS, et al. Effects of muscular strength on cardiovascular risk factors and prognosis. J Cardiopulm Rehabil Prev. 2012;32(6):351-358.

15. Smith JJ, Eather N, Morgan PJ, Plotnikoff RC, Faigenbaum AD, Lubans DR. The health benefits of muscular fitness for children and adolescents: a systematic review and meta-analysis. Sports Med. 2014;44(9):1209-1223.

16. Cooper R, Kuh D, Hardy R, Mortality Review Group. Objectively measured physical capability levels and mortality: systematic review and meta-analysis. BMJ. 2010;341(c4467.

17. Rantanen T. Muscle strength, disability and mortality. Scand J Med Sci Sports. 2003;13(1):3-8.

18. Sipola-Leppänen $M$, Vääräsmäki $M$, Tikanmäki $M$, Hovi $P$, Miettola $S$, Ruokonen $A$, et al. Cardiovascular Risk Factors in Adolescents Born Preterm. Pediatrics. 2014;134(4):e1072-1081.

19. Järvelin MR, Hartikainen-Sorri AL, Rantakallio P. Labour induction policy in hospitals of different levels of specialisation. Br J Obstet Gynaecol. 1993;100(4):310-315.

20. Miettola S, Hartikainen AL, Vaarasmaki M, Bloigu A, Ruokonen A, Jarvelin MR, et al. Offspring's blood pressure and metabolic phenotype after exposure to gestational hypertension in utero. Eur J Epidemiol. 2013;28(1):87-98.

21. Vääräsmäki $M$, Pouta A, Elliot $P$, Tapanainen $P$, Sovio $U$, Ruokonen $A$, et al. Adolescent Manifestations of Metabolic Syndrome Among Children Born to Women With Gestational Diabetes in a General-Population Birth Cohort. Am J Epidemiol. 2009;169(10):1209-1215. 
22. Pihkala J, Hakala T, Voutilainen P, Raivio K. [Characteristic of recent fetal growth curves in Finland]. Duodecim. 1989;105(18):1540-1546.

23. Sovijärvi A, Piirilä P, Korhonen O, Louhiluoto E, Pekkanen L. Spirometria- ja PEF-mittausten suoritus ja arviointi. Suomen kliinisen fysiologian yhdistyksen ja Suomen keuhko-lääkäriyhdistyksen suositus [Performing and evaluating spirometry and PEF measurements. Recommendation by the Finnish Society of Clinical Physiology and Finnish Society of Pulmonary Medicine]. Moodi. 2003;4(113.

24. Viljanen AA, Halttunen PK, Kreus KE, Viljanen BC. Spirometric studies in non-smoking, healthy adults. Scand J Clin Lab Invest Suppl. 1982;159( ):5-20.

25. Pellegrino R, Viegi G, Brusasco V, Crapo RO, Burgos F, Casaburi R, et al. Interpretative strategies for lung function tests. Eur Respir J. 2005;26(5):948-968.

26. Kantomaa MT, Stamatakis E, Kankaanpää A, Kaakinen M, Rodriguez A, Taanila A, et al. Physical activity and obesity mediate the association between childhood motor function and adolescents' academic achievement. Proc Natl Acad Sci U S A. 2013;110(5):1917-1922.

27. Tammelin T, Ekelund U, Remes J, Nayha S. Physical activity and sedentary behaviors among Finnish youth. Med Sci Sports Exerc. 2007;39(7):1067-1074.

28. Suni JH, Oja P, Laukkanen RT, Miilunpalo SI, Pasanen ME, Vuori IM, et al. Health-related fitness test battery for adults: aspects of reliability. Arch Phys Med Rehabil. 1996;77(4):399-405.

29. Suni JH RM, Ruiz JR. Retest Repeatability of Motor and Musculoskeletal Fitness Tests for Public Health Monitoring of Adult Populations. J Nov Physiother. 2014;4(1):1000194.

30. Stenholm S, Härkänen T, Sainio P, Heliövaara M, Koskinen S. Long-term Changes in Handgrip Strength in Men and Women-Accounting the Effect of Right Censoring Due to Death. J Gerontol A Biol Sci Med Sci. 2012;67(10):1068-1074.

31. Åstrand PO, Ryhming I. A nomogram for calculation of aerobic capacity (physical fitness) from pulse rate during sub-maximal work. J Appl Physiol. 1954;7(2):218-221.

32. Tammelin T, Nayha S, Rintamaki H. Cardiorespiratory fitness of males and females of northern Finland birth cohort of 1966 at age 31. Int J Sports Med. 2004;25(7):547-552.

33. Pulkkinen KR, Makinen T, Valkeinen H, Prattala R, Borodulin K. Educational differences in self-rated physical fitness among Finns. BMC Public Health. 2013;13(163.

34. Jaakkola JJ, Ahmed P, leromnimon A, Goepfert P, Laiou E, Quansah R, et al. Preterm delivery and asthma: a systematic review and meta-analysis. J Allergy Clin Immunol. 2006;118(4):823-830.

35. Strang-Karlsson S, Räikkönen K, Pesonen A-K, Kajantie E, Paavonen E, Lahti J, et al. Very Low Birth Weight and Behavioral Symptoms of Attention Deficit Hyperactivity Disorder in Young Adulthood: The Helsinki Study of Very-Low-Birth-Weight Adults. Am J Psychiatry. 2008;165(10):1345-1353.

36. Rantanen T, Guralnik JM, Foley D, et al. MIdlife hand grip strength as a predictor of old age disability. JAMA. 1999;281(6):558-560.

37. Silventoinen K, Magnusson PKE, Tynelius P, Batty GD, Rasmussen F. Association of body size and muscle strength with incidence of coronary heart disease and cerebrovascular diseases: a population-based cohort study of one million Swedish men. Int J Epidemiol. 2009;38(1):110-118.

38. Gale CR, Martyn CN, Cooper C, Sayer AA. Grip strength, body composition, and mortality. Int J Epidemiol. 2007;36(1):228-235.

39. Dodds R, Denison HJ, Ntani G, Cooper R, Cooper C, Sayer AA, et al. Birth weight and muscle strength: A systematic review and meta-analysis. J Nutr Health Aging. 2012;16(7):609-615.

40. Clemm H, Roksund O, Thorsen E, Eide GE, Markestad T, Halvorsen T. Aerobic capacity and exercise performance in young people born extremely preterm. Pediatrics. 2011;129(1):e97-e105.

41. Smith L, van Asperen PP, McKay KO, Selvadurai H, Fitzgerald DA. Reduced Exercise Capacity in Children Born Very Preterm. Pediatrics. 2008;122(2):e287-e293.

42. Vrijlandt EJLE, Gerritsen J, Boezen HM, Grevink RG, Duiverman EJ. Lung Function and Exercise Capacity in Young Adults Born Prematurely. Am J Respir Crit Care Med. 2006;173(8):890-896.

43. Kilbride HW, Gelatt MC, Sabath RJ. Pulmonary function and exercise capacity for ELBW survivors in preadolescence: effect of neonatal chronic lung disease. J Pediatr. 2003;143(4):488-493. 
44. Ridgway CL, Ong KK, Tammelin T, Sharp SJ, Ekelund U, Jarvelin MR. Birth size, infant weight gain, and motor development influence adult physical performance. Med Sci Sports Exerc.

2009;41(6):1212-1221.

45. Boreham CA, Murray L, Dedman D, Smith GD, Savage JM, Strain JJ. Birthweight and aerobic fitness in adolescents: the Northern Ireland Young Hearts Project. Public Health. 2001;115(6):373-379.

46. Salonen MK, Kajantie E, Osmond C, Forsen T, Yliharsila H, Paile-Hyvarinen M, et al. Developmental origins of physical fitness: the Helsinki Birth Cohort Study. PLoS One. 2011;6(7):e22302.

47. Germain JL, Hausenblas HA. The Relationship Between Perceived and Actual Physical Fitness: A Meta-Analysis. J Appl Sport Psychol. 2006;18(4):283-296.

48. Saigal S, Stoskopf B, Boyle M, Paneth N, Pinelli J, Streiner D, et al. Comparison of current health, functional limitations, and health care use of young adults who were born with extremely low birth weight and normal birth weight. Pediatrics. 2007;119(3):e562-573.

49. Okano G, Miyake H, Mori M. Leisure Time Physical Activity as a Determinant of Self-Perceived Health and Fitness in Middle-Aged Male Employees. J Occup Health. 2003;45(5):286-292.

50. Saarenpaa HK, Tikanmaki M, Sipola-Leppanen M, Hovi P, Wehkalampi K, Siltanen M, et al. Lung Function in Very Low Birth Weight Adults. Pediatrics. 2015;

51. Peykari N, Eftekhari MB, Tehrani FR, Afzali HM, Hejazi F, Atoofi MK, et al. Promoting Physical Activity Participation among Adolescents: The Barriers and the Suggestions. Int J Prev Med. 2015;6(12.

52. Telama R, Yang $X$, Leskinen E, Kankaanpaa A, Hirvensalo $M$, Tammelin $T$, et al. Tracking of physical activity from early childhood through youth into adulthood. Med Sci Sports Exerc. 2014;46(5):955962.

53. Gardner DS, Rhodes P. Developmental origins of obesity: programming of food intake or physical activity? Adv Exp Med Biol. 2009;646(83-93. 
Figure 1. Mean differences (95\% CIs, error bars) in preterm groups compared with controls (zero line). Adjustments: Model 1 (sex, age, cohort, bronchodilation [step test]), Model 2 (Model $1+$ parental education, maternal smoking, gestational diabetes, hypertensive disorder), Model 3 (Model $2+$ physical activity, asthma, height, body fat percentage, smoking). 
Table 1. Perinatal, neonatal, and current characteristics of the young adults born preterm and of the control group born at term.

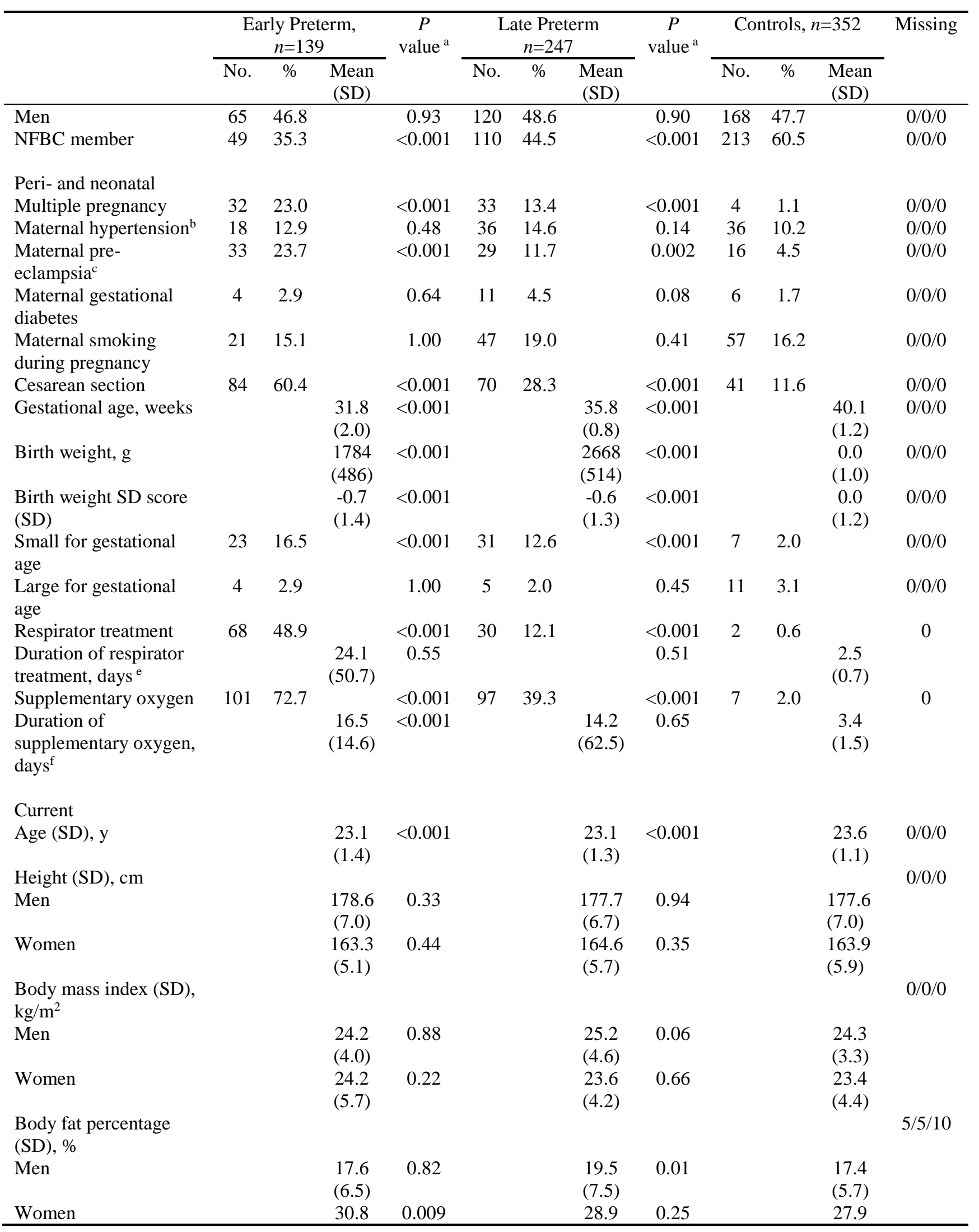




$\begin{array}{cccccccccc}63.2 & 0.92 & & & 63.4 & 0.77 & & & 63.1 & \\ (8.8) & & & & (8.4) & & & & (8.7) & \\ 44.2 & 0.68 & & & 45.1 & 0.37 & & & 44.5 & \\ (7.2) & & & & (5.8) & & & & (5.4) & \\ & 0.46 & & & & 0.58 & & & & 1 / 5 / 4 \\ & & 20 & 8.3 & & & 20 & 5.7 & & \\ & & 138 & 57.0 & & & 213 & 61.2 & & \\ & & 31 & 12.8 & & & 45 & 12.9 & & \\ & & 53 & 21.9 & & & 70 & 20.1 & & \\ 23.5 & 0.11 & & & 24.9 & 0.47 & & & 25.7 & 4 / 7 / 10 \\ (13.7) & & & & (14.6) & & & & (13.9) & \\ & 0.14 & 54 & 21.9 & & 0.95 & 75 & 21.3 & & 0 / 0 / 0 \\ & 1.000 & 0 & 0 & & 0.52 & 2 & 0.6 & & 0 / 0 / 0 \\ & 0.21 & 40 & 16.2 & & 0.94 & 55 & 15.6 & & 0 / 0 / 0 \\ & 0.002 & 78 & 31.6 & & 0.23 & 94 & 26.7 & & 0 / 0 / 0\end{array}$

Parental education

Basic or less

Secondary

Lower-level tertiary

Upper-level tertiary

Self-reported physical activity, METh/wk

Daily smoking

Use of beta blockers ${ }^{\mathrm{g}}$

Asthma

Bronchodilation test performed $^{\text {h }}$

$\begin{array}{cc}13 & 9.4 \\ 83 & 59.7 \\ 14 & 10.1 \\ 28 & 20.1 \\ & \\ & \\ 39 & 28.1 \\ 0 & 0 \\ 29 & 20.9 \\ 58 & 41.7\end{array}$

1) Abbreviations: METh/wk, metabolic equivalent hours per week.

a $P$ values refer to comparisons between preterm groups and controls, using Student's $t$-test or Pearson's chi-square test with Yates's continuity correction for 2-by-2 tables (and Fisher's exact test for use of beta blockers).

Level of statistical significance $P$ value $<0.05$.

${ }^{\mathrm{b}}$ Gestational or chronic hypertension.

${ }^{\mathrm{c}}$ Includes superimposed pre-eclampsia.

d Subjects whose mother's gestational diabetes data are missing include those whose mothers did not undergo an oral glucose tolerance test despite risk factors and thus have uncertain gestational diabetes status.

${ }^{\mathrm{e}}$ Mean (SD) duration of respirator treatment among those treated in respirator.

${ }^{\mathrm{f}}$ Mean (SD) duration of supplementary oxygen among those treated with supplementary oxygen.

g During the day before clinical visit.

${ }^{\mathrm{h}}$ During clinical visit. 
Table 2. Mean (SD) values of fitness measures in early preterm (<34 weeks), late preterm (34-36 weeks) and control ( $\geq 37$ weeks) group by sex.

\begin{tabular}{llllllll}
\hline & & Early preterm & Late preterm & \multicolumn{2}{l}{ Controls } \\
\cline { 3 - 7 } & & Mean (SD) & n & Mean (SD) & n & Mean (SD) & n \\
\hline Modified push-ups/40 s & Men & $13.9(4.0)$ & 62 & $13.7(4.0)$ & 115 & $14.8(3.2)$ & 157 \\
& Women & $10.2(3.0)$ & 68 & $10.3(2.8)$ & 112 & $10.8(3.3)$ & 169 \\
& All & $12.0(3.9)$ & 130 & $12.0(3.8)$ & 227 & $12.7(3.8)$ & 326 \\
Hand grip strength (N) & Men & $609.8(150.4)$ & 65 & $627.5(145.7)$ & 118 & $653.5(135.7)$ & 163 \\
& Women & $336.6(66.8)$ & 74 & $351.6(90.8)$ & 127 & $350(81)$ & 183 \\
& All & $464.3(177.7)$ & 139 & $484.5(183.1)$ & 245 & $492.9(187.5)$ & 346 \\
Heart rate after step test & Men & $155(16)$ & 62 & $153(16)$ & 115 & $153(15)$ & 160 \\
(beats/min) & & & & & & & \\
& Women & $161(14)$ & 70 & $160(15)$ & 117 & $160(14)$ & 168 \\
& All & $158(15)$ & 132 & $156(16)$ & 232 & $157(15)$ & 328 \\
Self-perceived fitness (scale 1-5) & Men & $2.4(1.0)$ & 62 & $2.5(0.9)$ & 117 & $2.7(0.8)$ & 163 \\
& Women & $2.2(0.9)$ & 73 & $2.5(0.8)$ & 123 & $2.4(0.8)$ & 179 \\
& All & $2.3(0.9)$ & 135 & $2.5(0.8)$ & 240 & $2.5(0.8)$ & 342 \\
\hline
\end{tabular}


SupplementalTable 1. Modified push-ups/40s, hand grip strength $(\mathrm{N})$, heart rate after step test (beats/min) and self-perceived fitness (scale 1-5, 1=very poor, $5=$ very good) in preterm groups compared with term-born controls.

\begin{tabular}{|c|c|c|c|c|c|c|c|c|c|c|}
\hline & \multicolumn{2}{|l|}{ Controls } & \multirow[t]{2}{*}{ Model $^{\mathbf{a}}$} & \multicolumn{2}{|l|}{ Early preterm } & \multirow[t]{2}{*}{$P$ value $^{\mathrm{b}}$} & \multicolumn{2}{|l|}{ Late preterm } & \multirow[t]{2}{*}{ p value ${ }^{b}$} & \multirow{2}{*}{$\begin{array}{l}\text { Total } \\
\text { N }\end{array}$} \\
\hline & Mean(SD) & $\mathbf{n}$ & & $\begin{array}{l}\text { Mean difference } \\
(95 \% \mathrm{CI})\end{array}$ & $\mathbf{n}$ & & $\begin{array}{l}\text { Mean difference } \\
(95 \% \mathrm{CI})\end{array}$ & $\mathbf{n}$ & & \\
\hline \multirow{4}{*}{$\begin{array}{l}\text { Modified push- } \\
\text { ups } / 40 \mathrm{~s}\end{array}$} & & 326 & & & 130 & & & 227 & & \\
\hline & $12.7(3.8)$ & & 1 & $-0.8(-1.5 ;-0.1)$ & & 0.02 & $-0.8(-1.4 ;-0.3)$ & & 0.005 & 683 \\
\hline & & & 2 & $-0.9(-1.6 ;-0.1)$ & & 0.03 & $-0.8(-1.4 ;-0.2)$ & & 0.008 & 683 \\
\hline & & & 3 & $-0.4(-1.1 ; 0.4)$ & & 0.33 & $-0.4(-1.0 ; 0.1)$ & & 0.12 & 654 \\
\hline \multirow{4}{*}{$\begin{array}{l}\text { Hand grip strength } \\
\text { (N) }\end{array}$} & & 346 & & & 139 & & & 245 & & \\
\hline & 492.9 (187.5) & & 1 & $-23.8(-46.8 ;-0.9)$ & & 0.04 & $-9.1(-28.1 ; 9.9)$ & & 0.35 & 730 \\
\hline & & & 2 & $-10.7(-35.0 ; 13.7)$ & & 0.39 & $3.4(-16.2 ; 23.0)$ & & 0.73 & 730 \\
\hline & & & 3 & $-13.1(-37.6 ; 11.5)$ & & 0.30 & $-2.0(-21.5 ; 17.6)$ & & 0.84 & 692 \\
\hline \multirow{4}{*}{$\begin{array}{l}\text { Heart rate after } \\
\text { step test (beats/min) }\end{array}$} & & 328 & & & 132 & & & 232 & & \\
\hline & $157(15)$ & & 1 & $0(-3 ; 3)$ & & 1.00 & $-1(-4 ; 2)$ & & 0.43 & 692 \\
\hline & & & 2 & $0(-4 ; 3)$ & & 0.89 & $-1(-4 ; 2)$ & & 0.41 & 692 \\
\hline & & & 3 & $-2(-5 ; 1)$ & & 0.24 & $-3(-5 ; 0)$ & & 0.02 & 659 \\
\hline \multirow{4}{*}{$\begin{array}{l}\text { Self-perceived } \\
\text { fitness (scale 1-5) }\end{array}$} & & 342 & & & 135 & & & 240 & & \\
\hline & $2.5(0.8)$ & & 1 & $-0.2(-0.4 ; 0.0)$ & & 0.02 & $0.0(-0.2 ; 0.1)$ & & 0.61 & 717 \\
\hline & & & 2 & $-0.2(-0.4 ; 0.0)$ & & 0.03 & $0.0(-0.2 ; 0.1)$ & & 0.91 & 717 \\
\hline & & & 3 & $-0.1(-0.2 ; 0.1)$ & & 0.40 & $0.1(0.0 ; 0.2)$ & & 0.22 & 697 \\
\hline
\end{tabular}

${ }^{a}$ Model 1: sex, age, cohort, and for step test: bronchodilation at clinical visit.

Model 2:Model 1+ SES, maternal smoking, gestational diabetes and hypertensive disorder during pregnancy, birth weight SD score.

Model 3:Model 2 + self-reported physical activity, diagnosed asthma, adult body size: height, body fat percentage, smoking.

${ }^{\mathrm{b}}$ Level of statistical significance $P$ value $<0.05$. 
Supplemental Table 2. Correlations between the outcomes among study participants.

\begin{tabular}{|c|c|c|c|c|c|c|c|c|c|c|}
\hline & & \multicolumn{3}{|c|}{ Hand grip strength $(\mathrm{N})$} & \multicolumn{3}{|c|}{$\begin{array}{l}\text { Heart rate after step test } \\
\text { (beats/min) }\end{array}$} & \multicolumn{3}{|c|}{$\begin{array}{l}\text { Self-perceived fitness } \\
(\text { scale 1-5) }\end{array}$} \\
\hline & & $\begin{array}{l}\text { Correlation } \\
\text { coefficient }\end{array}$ & $\begin{array}{l}P \\
\text { value }\end{array}$ & No. & $\begin{array}{l}\text { Correlation } \\
\text { coefficient }\end{array}$ & $\begin{array}{l}P \\
\text { value }\end{array}$ & No. & $\begin{array}{l}\text { Correlation } \\
\text { coefficient }\end{array}$ & $\begin{array}{l}P \\
\text { value }\end{array}$ & No. \\
\hline \multirow{4}{*}{$\begin{array}{l}\text { Modified } \\
\text { push- } \\
\text { ups/40s }\end{array}$} & All & 0.268 & $<0.001$ & 681 & -0.210 & $<0.001$ & 661 & 0.311 & $<0.001$ & 666 \\
\hline & $\begin{array}{l}\text { Early } \\
\text { preterm }\end{array}$ & 0.152 & 0.088 & 130 & -0.207 & 0.021 & 126 & 0.300 & 0.001 & 126 \\
\hline & $\begin{array}{l}\text { Late } \\
\text { preterm }\end{array}$ & 0.301 & $<0.001$ & 226 & -0.216 & 0.001 & 218 & 0.330 & $<0.001$ & 221 \\
\hline & Controls & 0.288 & $<0.001$ & 325 & -0.214 & $<0.001$ & 317 & 0.288 & $<0.001$ & 319 \\
\hline \multirow{4}{*}{$\begin{array}{l}\text { Hand grip } \\
\text { strength } \\
\text { (N) }\end{array}$} & All & & & & -0.124 & $<0.001$ & 692 & 0.150 & $<0.001$ & 712 \\
\hline & $\begin{array}{l}\text { Early } \\
\text { preterm }\end{array}$ & & & & -0.141 & 0.108 & 132 & 0.069 & 0.431 & 135 \\
\hline & $\begin{array}{l}\text { Late } \\
\text { preterm }\end{array}$ & & & & -0.090 & 0.173 & 231 & 0.153 & 0.018 & 239 \\
\hline & Controls & & & & -0.150 & 0.007 & 329 & 0.167 & 0.002 & 338 \\
\hline \multirow{4}{*}{$\begin{array}{l}\text { Heart rate } \\
\text { after step } \\
\text { test } \\
\text { (beats/min) }\end{array}$} & All & & & & & & 691 & -0.361 & $<0.001$ & 678 \\
\hline & $\begin{array}{l}\text { Early } \\
\text { preterm }\end{array}$ & & & & & & & -0.380 & $<0.001$ & 128 \\
\hline & $\begin{array}{l}\text { Late } \\
\text { preterm }\end{array}$ & & & & & & & -0.392 & $<0.001$ & 226 \\
\hline & Controls & & & & & & & -0.337 & $<0.001$ & 324 \\
\hline
\end{tabular}

Correlations were adjusted for sex and age.

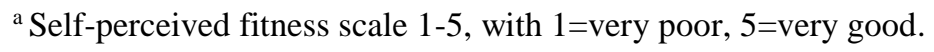


Supplemental Table 3. Covariates in association with the outcomes among study participants. Mean differences (95\% CI) of the outcomes compared with the reference group or one unit higher value adjusted for sex, age and cohort selection.

\begin{tabular}{|c|c|c|c|c|c|c|c|c|c|c|c|c|}
\hline & \multicolumn{3}{|c|}{ Modified push-ups/40s (N=683) } & \multicolumn{3}{|c|}{ Hand grip strength $(N)(N=730)$} & \multicolumn{3}{|c|}{$\begin{array}{l}\text { Heart rate after step test } \\
\text { (beats/min) }(\mathrm{N}=692)\end{array}$} & \multicolumn{3}{|c|}{$\begin{array}{l}\text { Self-perceived fitness; scale } 1 \\
\text { (lowest) to } 5 \text { (highest) }(\mathrm{N}=717)\end{array}$} \\
\hline & $\begin{array}{l}\text { Mean } \\
\text { difference } \\
(95 \% \mathrm{CI})\end{array}$ & $P$ value & No. & $\begin{array}{l}\text { Mean difference } \\
(95 \% \mathrm{CI})\end{array}$ & $P$ value & No. & $\begin{array}{l}\text { Mean } \\
\text { difference } \\
(95 \% \mathrm{CI})\end{array}$ & $P$ value & No. & $\begin{array}{l}\text { Mean } \\
\text { difference } \\
(95 \% \mathrm{CI})\end{array}$ & $\begin{array}{l}P \\
\text { value }\end{array}$ & No. \\
\hline \multicolumn{13}{|l|}{ Sex } \\
\hline Male & $3.7(3.2 ; 4.2)$ & $\begin{array}{l}<0.001 * \\
* *\end{array}$ & 334 & $\begin{array}{l}287.9(271.0 \\
304.4)\end{array}$ & $\begin{array}{l}<0.001 \\
* * *\end{array}$ & 346 & $-7(-8 ;-4)$ & $\begin{array}{l}<0.001 * \\
* *\end{array}$ & 337 & $-0.2(-0.3 ;-0.1)$ & $\begin{array}{l}0.001 * \\
* *\end{array}$ & 342 \\
\hline Female & Referent & & 349 & Referent & & 384 & Referent & & 355 & Referent & & 375 \\
\hline Age & $0.0(-0.3 ; 0.3)$ & 0.84 & 683 & $0.8(-8.5 ; 10.1)$ & 0.86 & 730 & $0(-2 ; 1)$ & 0.49 & 692 & $0.0(0.0 ; 0.1)$ & 0.18 & 717 \\
\hline Cohort & & & & & & & & & & & & 717 \\
\hline FMBR & Referent & & 341 & Referent & & 363 & Referent & & 346 & Referent & & 354 \\
\hline NFBC & $-0.2(-0.9 ; 0.5)$ & 0.50 & 342 & $17.0(-6.3 ; 40.3)$ & 0.15 & 367 & $-2(-5 ; 1)$ & 0.27 & 346 & $0.0(-0.2 ; 0.2)$ & 0.90 & 363 \\
\hline Bronchodilation test $^{\text {a }}$ & $-0.3(-0.8 ; 0.3)$ & 0.30 & 683 & $-7.3(-25.4 ; 10.7)$ & 0.43 & 730 & $4(2 ; 7)$ & $\begin{array}{l}<0.001 * \\
* *\end{array}$ & 692 & $-0.1(-0.3 ; 0.0)$ & $0.03 *$ & 717 \\
\hline \multicolumn{13}{|l|}{$\begin{array}{l}\text { Parental educational } \\
\text { level }\end{array}$} \\
\hline Basic or less & $-1.7(-2.8 ;-0.6)$ & $0.003 * *$ & 47 & $4.2(-32.0 ; 40.5)$ & 0.82 & 52 & $2(-3 ; 7)$ & 0.37 & 49 & $-0.3(-0.6 ;-0.0)$ & 0.03 & 51 \\
\hline Secondary & $-1.0(-1.7 ;-0.4)$ & $0.002 * *$ & 402 & $0.7(-20.7 ; 22.1)$ & 0.95 & 431 & $2(0 ; 6)$ & 0.06 & 404 & $-0.2(-0.4 ;-0.1)$ & 0.007 & 427 \\
\hline Lower-level tertiary & $-0.8(-1.7 ; 0.2)$ & 0.10 & 85 & $1.3(-28.7 ; 31.4)$ & 0.93 & 90 & $1(-3 ; 5)$ & 0.563 & 87 & $0.0(-0.3 ; 0.2)$ & 0.77 & 88 \\
\hline Upper-level tertiary & Referent & & 142 & Referent & & 149 & Referent & & 145 & Referent & & 150 \\
\hline Missing & $-2.0(-4.6 ; 0.6)$ & 0.12 & 7 & $\begin{array}{l}-83.4(-165.1 ;- \\
1.6)\end{array}$ & $0.05 *$ & 8 & $4.5(-7 ; 16)$ & 0.43 & 7 & $-1.6(-3.3 ; 0.1)$ & 0.06 & 1 \\
\hline \multicolumn{13}{|l|}{$\begin{array}{l}\text { Maternal smoking } \\
\text { during pregnancy }\end{array}$} \\
\hline No & Referent & & 557 & Referent & & 588 & Referent & & 558 & Referent & & 578 \\
\hline Yes & $-0.9(-1.6 ;-0.2)$ & $0.008 * *$ & 112 & $-6.8(-29.1 ; 15.5)$ & 0.55 & 125 & $0(-3 ; 3)$ & 0.94 & 118 & $-0.1-0.2 ; 0.1)$ & 0.45 & 122 \\
\hline Missing & $1.5(-0.3 ; 3.3)$ & 0.10 & 14 & $-11.7(-67.3 ; 44.0)$ & 0.68 & 17 & $-3(-10 ; 4)$ & 0.43 & 16 & $0.2(-0.2 ; 0.6)$ & 0.35 & 17 \\
\hline $\begin{array}{l}\text { Maternal gestational } \\
\text { diabetes }\end{array}$ & & & & & & 730 & & & & & & 717 \\
\hline No GDM & Referent & & 614 & Referent & & 655 & Referent & & 622 & Referent & & 53 \\
\hline GDM & $-0.9(-2.5 ; 0.6)$ & 0.24 & 19 & $-37.2(-87.1 ; 12.8)$ & 0.14 & 21 & $3(-4 ; 10)$ & 0.45 & 18 & $-0.4(0.8 ; 0.0)$ & $0.03 *$ & 644 \\
\hline Missing & $-0.7(-1.7 ; 0.3)$ & 0.18 & 50 & $-7.9(-41.1 ; 25.3)$ & 0.64 & 54 & $-3.5(-8 ; 1)$ & 0.12 & 52 & $0.1(-0.2 ; 0.3)$ & 0.69 & 20 \\
\hline $\begin{array}{l}\text { Maternal hypertensive } \\
\text { disorder during } \\
\text { pregnancy }\end{array}$ & & & & & & & & & & & & 717 \\
\hline $\begin{array}{l}\text { No maternal } \\
\text { hypertensive disorder }\end{array}$ & Referent & & 517 & Referent & & 553 & Referent & & 521 & Referent & & 544 \\
\hline Maternal hypertension ${ }^{b}$ & $-0.4(-1.2 ; 0.4)$ & 0.34 & 84 & $-10.8(-36.5 ; 14.8)$ & 0.41 & 89 & $2(-2 ; 5)$ & 0.34 & 85 & $-0.1(-0.3 ; 0.1)$ & 0.17 & 88 \\
\hline
\end{tabular}




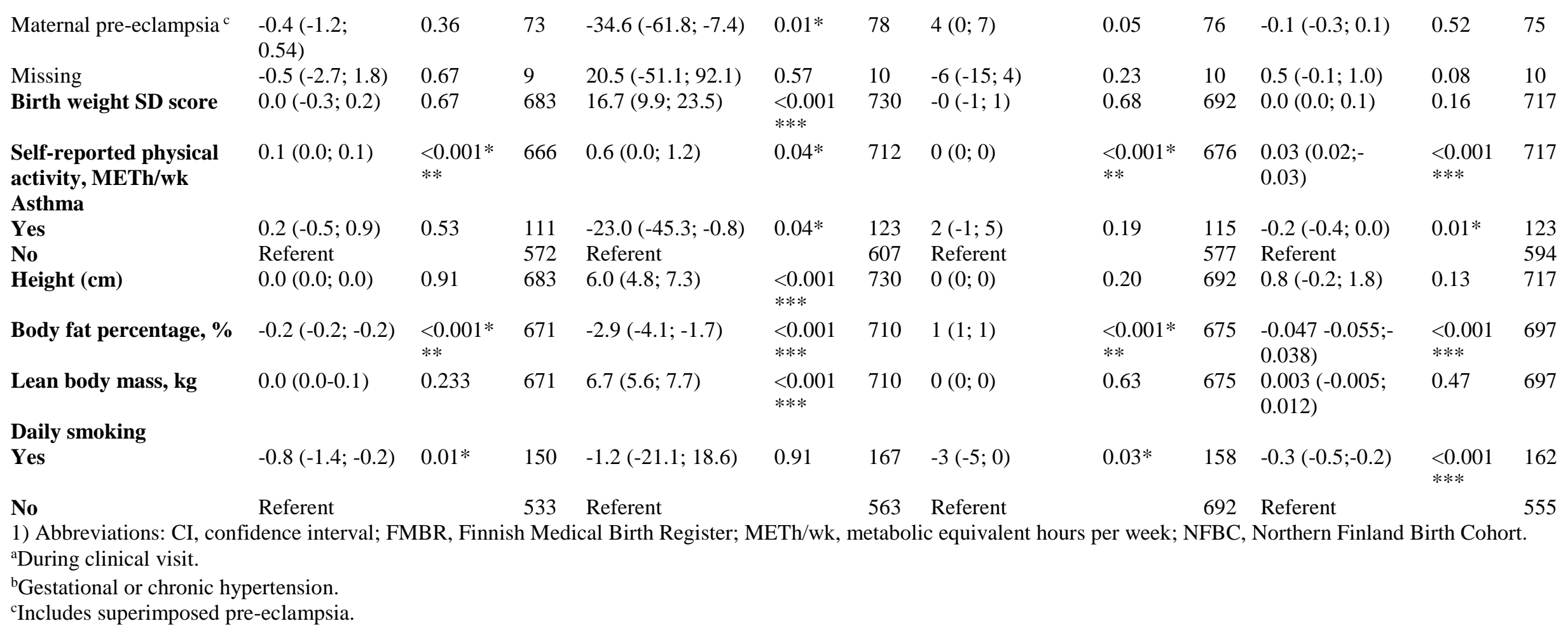



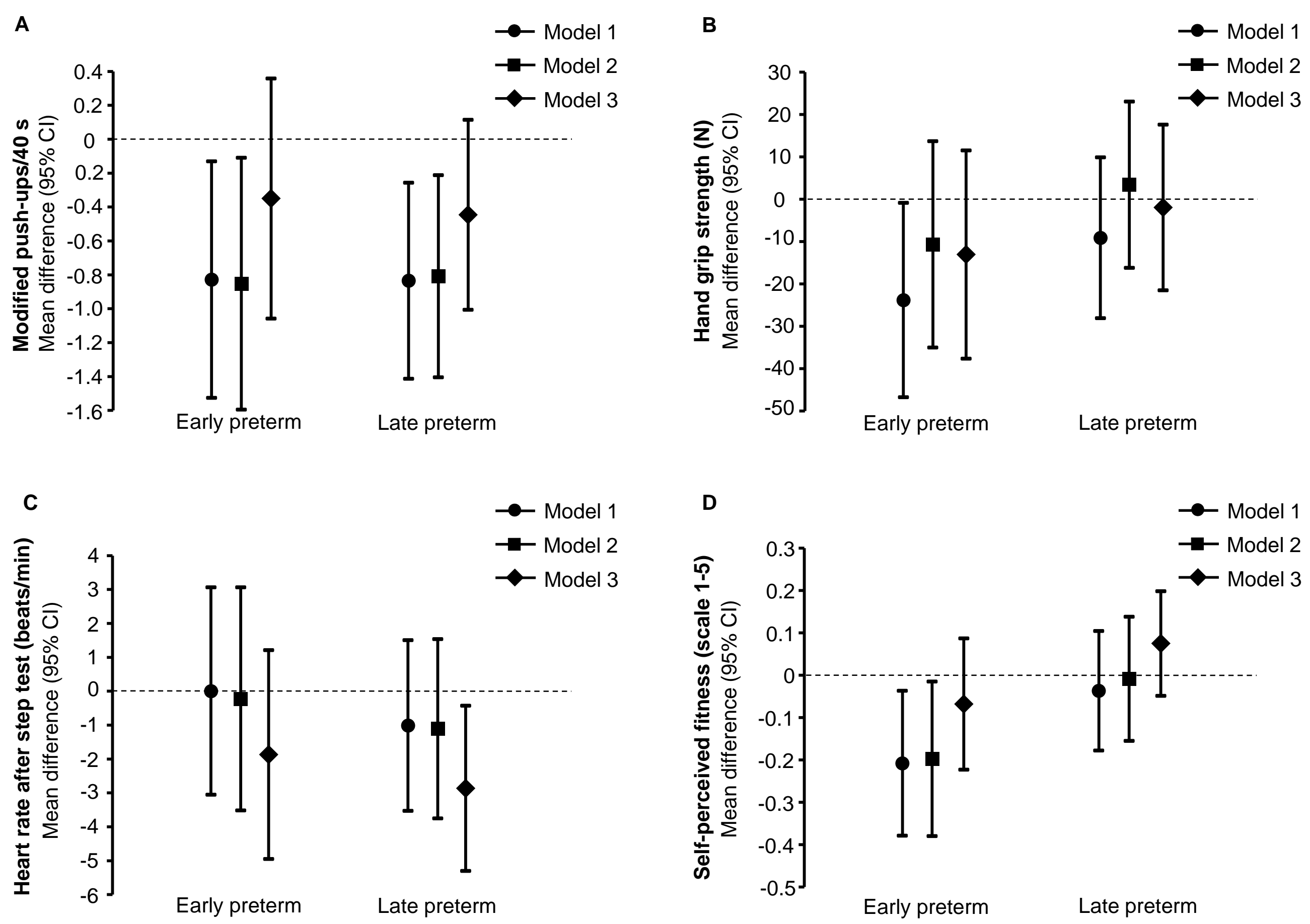


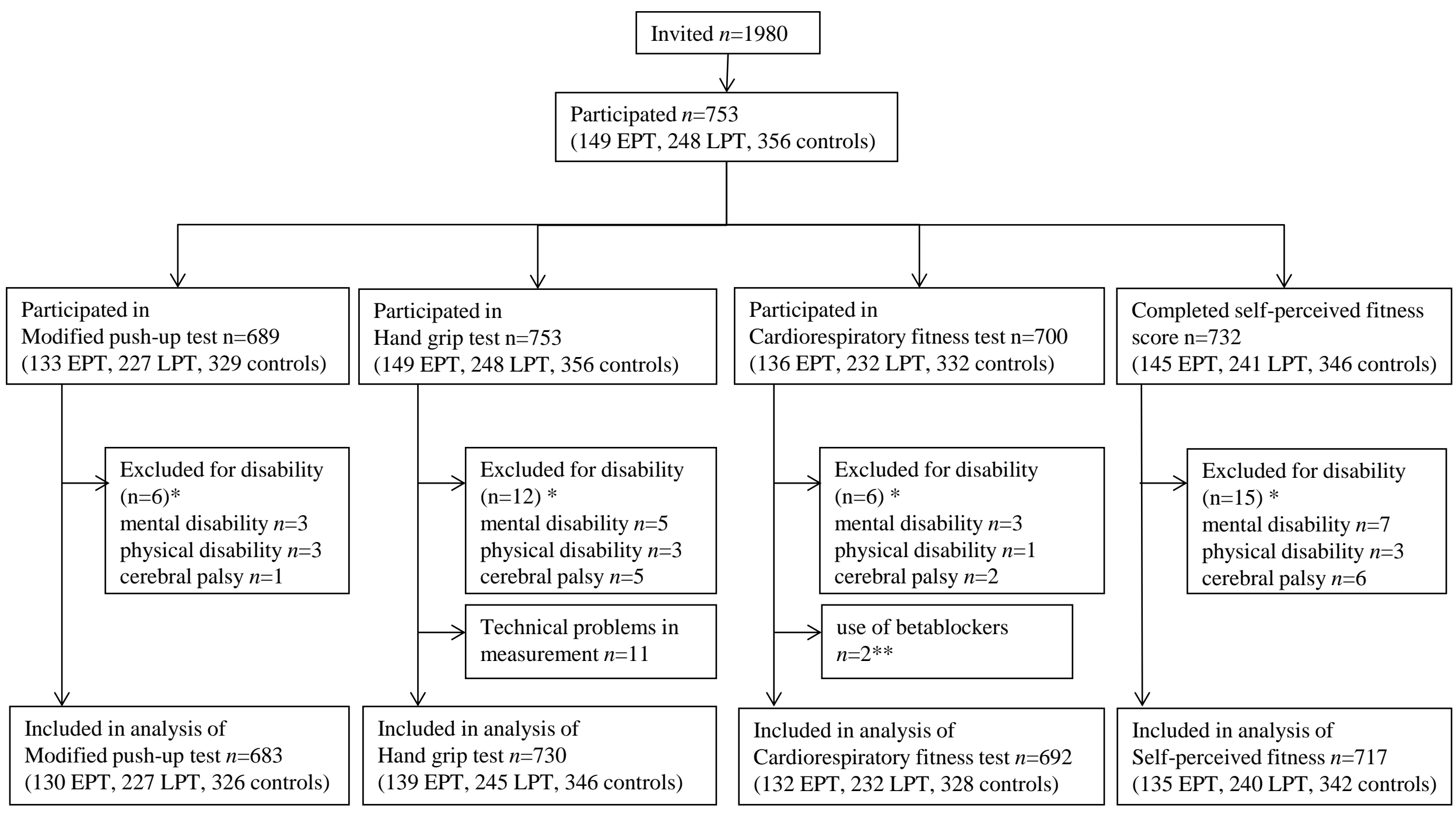

* One person can have more than one reason for exclusion

**During the day before clinical visit. 